\title{
An optimal scheduling method for integrated power and heat system with multiple thermal flexibilities
}

\author{
Da Lin ${ }^{1, *}$, Chouwei $\mathrm{Ni}^{2}$, Xuesong Zhang ${ }^{2}$ and Junhao Huang ${ }^{3}$ \\ ${ }^{1}$ Electrical Technology Department, Hangzhou Yineng Electric Power Technology Co., Ltd, Hangzhou, China \\ 2 Energy Internet Lab, State Grid Zhejiang Electric Power Ltd, Hangzhou, China \\ ${ }^{3}$ Production Technology Department, Hangzhou Yineng Electric Power Technology Co., Ltd, Hangzhou, China
}

\begin{abstract}
Integrated power and heat system (IPHS) is a typical multi-energy system which involves power system and district heating system (DHS). The utilization of thermal flexibilities in the joint operation of power system and district heating system has shown the potential to improve energy efficiency and economic performance. In this paper, an optimal scheduling method for IPHS with multiple thermal flexibilities is proposed. Thermal flexibilities of electric boilers and district heating network (DHN) are modelled and analysed, in which the flexibility of DHN is described by a detailed node-based quasidynamic model. The proposed scheduling method is to minimize the operation cost of IPHS. Case study is carried out on a typical IPHS with a 6-node power system and a 12-node DHS. Simulation results show that the scheduling method can reduce the operation cost of IPHS and improve wind accommodation.
\end{abstract}

\section{Introduction}

Integrated power and heat system (IPHS) is one of the most common form of multi-energy system, which combine power system and district heating system (DHS) [1], as shown in Fig. 1. And thermal flexibilities in IPHS can improve economic efficiency, system reliability and wind accommodation [2].

Thermal flexibility is a promising option to improve IPHS operation performance, which has increasingly gained attention. On the one hand, thermal equipment such as electric boiler, heat pump and thermal storage device can offer thermal flexibility. A scheme of configuring electric boilers for thermal power plants to increase wind power accommodation is evaluated in [3]. Energy balance in IPHS integrated with large capacity thermal energy storage is analysed in [4]. On the other hand, thermal inertia of district heating network (DHN) can offer additional operational flexibility of heat source. A unit commitment model of IPHS considering the thermal inertia of DHN is proposed in [5], which improves wind power accommodation. An MLIP model to evaluation the annual performance of DHS to use DHN flexibility as short-term thermal energy storage is proposed in [6].

This paper proposed an optimal scheduling method for IPHS with multiple thermal flexibilities. In the following sections, flexibility from DHN is analysed and described as a quasi-dynamic model. Then the optimal scheduling model is proposed and testes on a IPHS with a 6-node power system and a 12-node DHS. Case study verifies the effectiveness of our scheduling model.

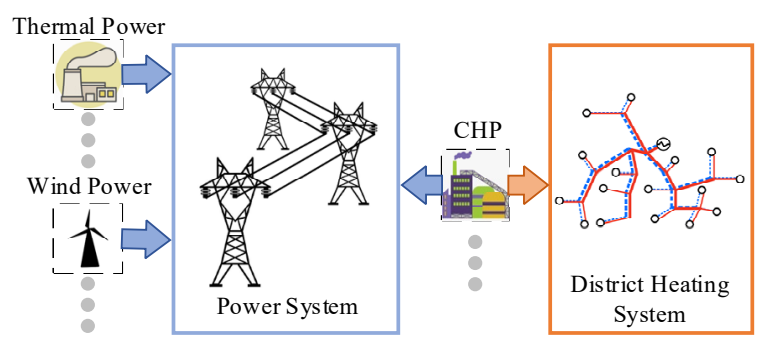

Fig. 1. Structure of PIHS

\section{Modelling of DHN}

DHN flexibility originates from its heat storage capacity and the transmission delay of heat carrier. Because the timescale of transmission delay is usually larger than that of dispatch interval, static thermal equation is unable to describe the thermal dynamics of DHN [7]. Thus, a quasi-dynamic DHN model is essential to the IPHS scheduling method. The detailed formulation of the quasi-dynamic DHN model is shown in Section 2.1-2.3.

As shown in Fig. 2, DHN is composed of primary pipe network and secondary pipe network, which is similar to transmission network and distribution network in power system. The primary pipe network is not connected directly to the secondary pipe network in $\mathrm{DHN}$, and thermal energy is exchanged through a heatexchanger station. Because the heat storage capacity of primary pipe network is considerably larger than that of secondary pipe network, only the thermal dynamics in primary pipe network is considered. Besides, each heatexchanger station and the following secondary pipe networks are denoted as a heat load.

\footnotetext{
${ }^{*}$ Corresponding author: 1d2009ee@163.com
} 


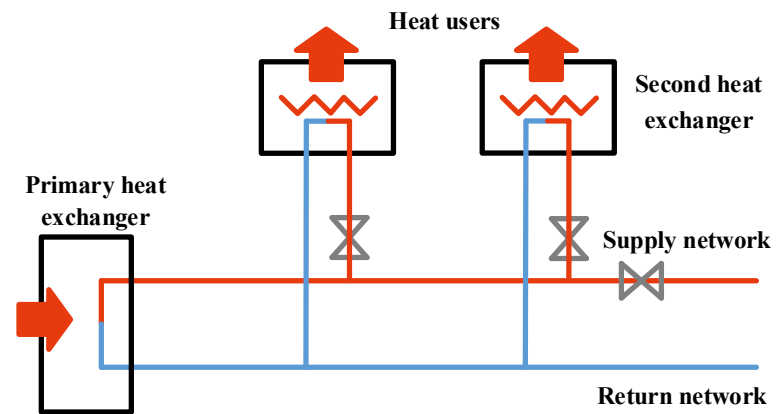

Fig. 2. Scheme diagram of DHN

\subsection{Primary pipeline model}

The quasi-dynamic pipeline model needs to reflect transmission delay and heat loss character of pipelines. Transmission delay of a pipeline is the time interval that heat carrier needs to flow from the inlet to the outlet. In this paper DHS is assumed to operate in a constant flow rate mode, in which the transmission delay is constant in the dispatch process. The calculation of transmission delay is stated as:

$$
\tau_{j}=\frac{l_{j}}{3600 v_{j}}
$$

where $\tau_{j}$ is the transmission delay of pipeline $j, \mathrm{~h} ; l_{j}$ is the length of pipeline $j, \mathrm{~m} ; v_{j}$ is the velocity of heat carrier, $\mathrm{m} / \mathrm{s}$.

Taking transmission delay into account, the relationship between inlet temperature and outlet temperature can be denoted as:

$$
T_{t, j}^{\text {out }}{ }^{\prime}=T_{t-\tau_{j}, j}^{\text {in }}
$$

where $T_{t, j}^{\text {out ' }}$ is the outlet temperature of pipe $j$ at time $t$ that ignore transmission loss, ${ }^{\circ} \mathrm{C} ; T_{t-\tau_{j}, j}^{\text {in }}$ is the inlet temperature of pipe $j$ at time $\left(t-\tau_{j}\right),{ }^{\circ} \mathrm{C}$.

Transmission loss occurs when heat carrier flows through the pipeline, and it is related to heat loss coefficient and ambient temperature, which is formulated as follow:

$$
\begin{gathered}
T_{t, j}^{\text {out }}=\left(T_{t, j}^{\text {out }}-T_{t}^{a m}\right) e^{-a l_{j}}+T_{t}^{a m} \\
a=k_{j} /\left(q_{j} \mathcal{C}_{\mathrm{w}}\right)
\end{gathered}
$$

where $T_{t, j}^{\text {out }}$ is the outlet temperature of pipeline $j$ at time $t,{ }^{\circ} \mathrm{C} ; T_{t}^{a m}$ is the ambient temperature at time $t,{ }^{\circ} \mathrm{C}$; $k_{j}$ is the heat loss coefficient of pipeline $j, \mathrm{~W} /\left(\mathrm{m} \cdot{ }^{\circ} \mathrm{C}\right)$; $c_{\mathrm{w}}$ is the specific heat capacity of heat carrier, $\mathrm{kJ} /\left(\mathrm{kg} \cdot{ }^{\circ} \mathrm{C}\right) ; q_{j}$ is the mass flow rate of heat carrier in pipe line $j, \mathrm{~kg} / \mathrm{s}$.

\subsection{Temperature mixing model}

According to the thermal energy conservation, the thermal energy flowing into one node is equal with the thermal energy flowing out. The temperature mixing can be concluded as:

$$
\sum_{j \in S_{n}^{\text {pipe- }}} T_{\tau, j}^{\text {out }} q_{\tau, j}=T_{\tau, k}^{\text {in }} \sum_{k \in S_{n}^{\text {pipet }}} q_{\tau, k}
$$

where $\boldsymbol{S}_{n}^{\text {pipe- }}$ and $\boldsymbol{S}_{n}^{\text {pipe+ }}$ are the sets of pipelines starting from node $n$ and pipelines ending at node $n$, respectively.

In addition, the thermal carrier in the DHN should satisfy the node continuity equation: the amount of the fluid flowing into one node is equal with the fluid flowing out, which can be denoted as:

$$
\sum_{j \in S_{n}^{\text {pipe }}} q_{\tau, j}=\sum_{k \in S_{n}^{\text {pipet }}} q_{\tau, k}
$$

\subsection{Heat-exchanger station model}

The heat-exchanger station realizes the heat transfer between primary pipelines and secondary pipelines in the DHN, which can specifically meet the demand of the user's heat load by adjusting the flow rate in the secondary network. The heat exchange of heatexchanger station is formulated as:

$$
\begin{gathered}
Q_{t, i}=c_{\mathrm{w}} m_{t, i}\left(T_{t, i}^{\mathrm{supply}}-T_{t, i}^{\mathrm{return}}\right) \\
Q_{t, i}^{\mathrm{load}} \Delta t=Q_{t, i}
\end{gathered}
$$

where $Q_{t, i}$ is the heat exchanged of the heat-exchanger station $i$ at time period $t, \mathrm{~kJ} ; m_{t, i}$ is the quality of heat carrier that flows through heat-exchanger station $i$ at time period $t, \mathrm{~kg} ; T_{t, i}^{\text {supply }}$ and $T_{t, i}^{\text {return }}$ are the supply and return temperature of the heat-exchanger station $i$ at time period $t,{ }^{\circ} \mathrm{C} ; Q_{t, i}^{\text {load }}$ is the heat load at load $i$ at time period $t, \mathrm{~kW}$.

\section{Optimal scheduling of IPHS}

\subsection{Objective function}

The optimal scheduling model of the IPHS with multiple thermal flexibilities has the objective function to minimize the total operational cost of the IPHS. At the same time, in order to promote the accommodation of wind power, the penalty cost of wind curtailment is added to the total operating cost, which reflects the principle of giving priority to the wind power. The expression of the objective function is stated as:

$$
\begin{gathered}
\min C=\sum_{t \in N}\left(C_{t}^{\mathrm{CHP}}+C_{t}^{\mathrm{TU}}+C_{t}^{\text {wind }}\right) \\
C_{t}^{\text {wind }}=K_{\text {cut }}\left(P_{t, \text { pre }}^{\text {wind }}-P_{t}^{\text {wind }}\right)
\end{gathered}
$$

where $C_{t}^{\mathrm{CHP}}$ is the operational cost of CHP units at time period $t$, yuan; $C_{t}^{T U}$ is the operational cost of thermal units at time period $t$, yuan; $C_{t}^{\text {wind }}$ is the cost of wind curtailment at time period $t$, yuan; $K_{\text {cut }}$ is the coefficient of wind curtailment penalty, yuan $/ \mathrm{kW} ; P_{t, \text { pre }}^{\text {wind }}$ is the forecasted wind power at time period $t, \mathrm{~kW}$; $P_{t}^{\text {wind }}$ is the actual wind power at time period $t, \mathrm{~kW}$. 


\subsection{Constraints}

\subsubsection{Power system constraints}

System level constraints for power system include power balance constraint, power flow constraint and spinning reserve constraint. Power balance constraint guarantee the safety and efficiency of power system, as shown in below:

$$
P_{t}^{\mathrm{CHP}}+P_{t}^{\mathrm{TU}}+P_{t}^{\mathrm{wind}}-P_{t}^{\mathrm{EB}}=\sum_{i \in S^{\mathrm{laad}}} P_{t, i}^{\mathrm{load}}
$$

where $P_{t}^{\mathrm{CHP}}$ is the power output of CHP units at time period $t, \mathrm{~kW} ; P_{t}^{\mathrm{TU}}$ is the power output of thermal units at time period $t, \mathrm{~kW} ; P_{t}^{\mathrm{EB}}$ is the power consumption of electric boilers at time period $t, \mathrm{~kW} ; P_{t, i}^{\text {load }}$ is the power demand of load $i$ at time period $t, \mathrm{~kW} ; S^{\text {load }}$ denote the set of load nodes.

Power in each branch is bounded by the power flow constraint, denoted as:

$$
\underline{P}_{i}^{\text {line }} \leq P_{i, t}^{\text {line }} \leq \bar{P}_{i}^{\text {line }}
$$

where $\underline{P}_{i}^{\text {line }}$ and $\bar{P}_{i}^{\text {line }}$ are the lower and upper power flow limit of branch $i, \mathrm{~kW} ; P_{i, t}^{\text {line }}$ is the power flow of branch $i$ at time period $t, \mathrm{~kW}$.

Thermal units are required to keep enough spinning reserve to meet the system reserve level, which can be stated as:

$$
\begin{gathered}
\sum_{i=1}^{n} P_{d o w n, i, t}^{\mathrm{TU}} \geq r_{d o w n, t}^{\mathrm{sy}} \\
\sum_{i=1}^{n} P_{u p, i, t}^{\mathrm{TU}} \geq r_{u p, t}^{\mathrm{sys}}
\end{gathered}
$$

where $P_{d o w n, i, t}^{\mathrm{TU}}$ and $P_{u p, i, t}^{\mathrm{TU}}$ are the down and up spinning reserve offered by thermal unit $i$ at time period $t, \mathrm{~kW}$; $r_{d o w n, t}^{\mathrm{sys}}$ and $r_{u p, t}^{\mathrm{sys}}$ are the minimum spinning reserve required by power system at time period $t, \mathrm{~kW}$.

\subsubsection{DHS constraints}

In addition to (3), (5)-(7), DHS also need temperature constraints for supply and return heat carrier, which is denoted as:

$$
\begin{aligned}
& T_{i, \text { min }}^{\text {suply }} \leq T_{i}^{\text {supply }} \leq T_{i, \text { max }}^{\text {suply }} \\
& T_{i, \text { min }}^{\text {return }} \leq T_{i}^{\text {return }} \leq T_{i, \text { max }}^{\text {retur }}
\end{aligned}
$$

where $T_{i}^{\text {supply }}$ and $T_{i}^{\text {return }}$ are supply and return temperature at heat-exchanger station $i,{ }^{\circ} \mathrm{C} ; T_{i, \text { max }}^{\text {suply }}$ and $T_{i, \min }^{\text {suply }}$ are the upper and lower limit of supply temperature, ${ }^{\circ} \mathrm{C} ; T_{i, \max }^{\text {return }}$ and $T_{i, \min }^{\text {retur }}$ are the upper and lower limit of return temperature, ${ }^{\circ} \mathrm{C}$.

\subsubsection{Generation constraints}

CHP, thermal unit, wind turbine and electric boiler are considered in the proposed scheduling method, and their constraints are shown as follows.

1)CHP

Back-pressure CHP has a fixed power-to-heat ratio, its power and heat output constraints is stated as:

$$
\left\{\begin{array}{l}
P_{t}^{\mathrm{CHP}}=k_{m} Q_{t}^{\mathrm{CHP}} \\
P_{\min }^{\mathrm{CHP}} \leq P_{t}^{\mathrm{CHP}} \leq P_{\max }^{\mathrm{CHP}}
\end{array}\right.
$$

where $Q_{t}^{\mathrm{CHP}}$ is the heat output of CHP at time period $t$, $\mathrm{kW} ; P_{\max }^{\mathrm{CHP}}$ and $P_{\min }^{\mathrm{CHP}}$ are the maximum and minimum power output of CHP, $\mathrm{kW} ; k_{m}$ is power-to-heat ratio. CHP ramping constraint is stated as:

$$
-D_{\mathrm{UD}, \text { max }}^{\mathrm{CHP}} \leq P_{t+1}^{\mathrm{CHP}}-P_{t}^{\mathrm{CHP}} \leq U_{\mathrm{UR}, \text { max }}^{\mathrm{CHP}}
$$

where $U_{\mathrm{UR} \text {, } \operatorname{cax}}^{\mathrm{CHP}}$ and $D_{\mathrm{UD}, \text { max }}^{\mathrm{CHP}}$ are the maximum upwards and downwards ramping rate of $\mathrm{CHP}, \mathrm{kW}$.

2)Thermal unit

Thermal unit constraints include power limit and ramping limit, as shown below:

$$
\begin{gathered}
P_{\text {min }}^{\mathrm{TU}} \leq P_{t}^{\mathrm{unit}} \leq P_{\text {max }}^{\mathrm{TU}} \\
-D_{U D, \text { max }}^{\mathrm{TU}} \leq P_{t+1}^{\mathrm{TU}}-P_{t}^{\mathrm{TU}} \leq U_{U R, \text { max }}^{\mathrm{TU}}
\end{gathered}
$$

where $P_{\max }^{\mathrm{TU}}$ and $P_{\min }^{\mathrm{TU}}$ are the maximum and minimum power output of thermal unit, $\mathrm{kW} ; U_{U R, \max }^{\mathrm{TU}}$ and $D_{U D, \text { max }}^{\mathrm{TU}}$ are the maximum upwards and downwards ramping rate of thermal, $\mathrm{kW}$.

3)Wind turbine

The actual power output of wind turbine is lower than the predict power output:

$$
0 \leq P_{t}^{\text {wind }} \leq P_{t, \mathrm{pre}}^{\mathrm{win}}
$$

4)Electric boiler

The electric boiler constraints are formulated as bellow:

$$
\begin{gathered}
Q_{t}^{E B}=\eta^{E B} P_{t}^{E B} \\
P_{\min }^{E B} \leq P_{t}^{E B} \leq P_{\max }^{E B}
\end{gathered}
$$

where $Q_{t}^{E B}$ is the heat output of electric boiler at time period $t, \mathrm{~kW} ; \eta^{E B}$ is the efficiency of electric boiler; $P_{\max }^{E B}$ and $P_{\min }^{E B}$ are the maximum and minimum heat output of electric boiler, $\mathrm{kW}$

\section{Case study}

\subsection{Case structure}

In this paper, a 6-node electric power system and a 12node heating system are used as a test system [8], and the structure is shown in Fig. 3. The second heatexchanger stations are built at $\mathrm{Nd1} \sim 7$, and the first heat exchange station are built at $\mathrm{Nd} 8$. The heating network 
pipeline parameters are shown in Table 1. The electrothermal coupling equipment includes CHP units and electric boilers located at grid node 6/heating network node 8. Electricity load, heat load and wind power forecast output are shown in Fig. 4 [9], the parameters of the system's conventional units, CHP units and electric boilers are shown in Table 2 [10]. The scheduling period is $24 \mathrm{~h}$, and the scheduling interval is $1 \mathrm{~h}$. The heating network temperature can still return to the initial value after a scheduling cycle.

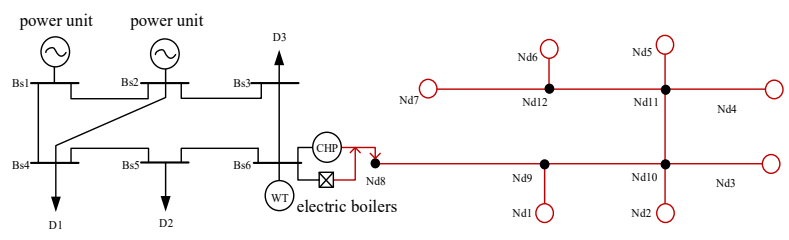

Fig. 3. Diagram of electric-heat integrated energy system structure

Table 1. 12-node heating system pipeline parameters

\begin{tabular}{ccccc}
\hline pipeline & $\begin{array}{c}\text { First } \\
\text { node }\end{array}$ & $\begin{array}{c}\text { End } \\
\text { node }\end{array}$ & $\begin{array}{c}\text { Length } \\
/(\mathrm{m})\end{array}$ & $\begin{array}{c}\text { Flow } \\
/\left(\mathrm{m}^{3} / \mathrm{h}\right)\end{array}$ \\
\hline 1 & 8 & 9 & 1000 & 7000 \\
2 & 9 & 1 & 250 & 1000 \\
3 & 9 & 10 & 700 & 6000 \\
4 & 10 & 2 & 250 & 1000 \\
5 & 10 & 3 & 700 & 1000 \\
6 & 10 & 11 & 500 & 4000 \\
7 & 11 & 4 & 700 & 1000 \\
8 & 11 & 5 & 250 & 1000 \\
9 & 11 & 12 & 700 & 2000 \\
10 & 12 & 6 & 250 & 1000 \\
11 & 12 & 7 & 700 & 1000 \\
\hline
\end{tabular}

Table 2. Power equipment parameters

\begin{tabular}{ccc}
\hline Node & Power output/(MW) & Type \\
\hline 1 & 450 & Power unit \\
2 & 250 & Power unit \\
6 & 300 & CHP unit \\
6 & 30 & Electric boilers \\
\hline
\end{tabular}

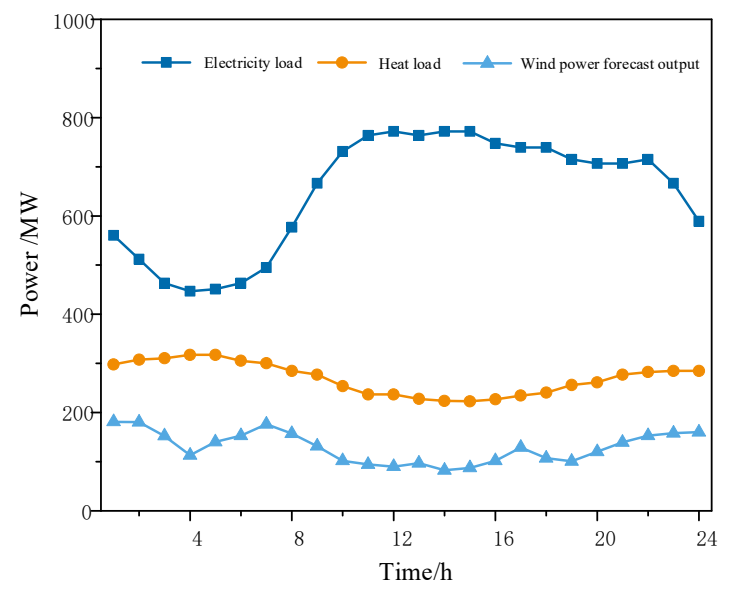

Fig. 4. Electricity load, heat load and wind power forecast output
To demonstrate the effect of optimal scheduling method for IPHS with multiple thermal flexibilities, three cases are introduced.

Case I is the proposed model in this paper, which considers thermal flexibilities of electric boilers and DHN.

Case II considers thermal flexibilities of DHN, without electric boilers.

Case III ignores thermal flexibilities of electric boilers and DHN.

\subsection{Economic analysis}

The comparison results of the costs under the above three cases are shown in Table 3 during a dispatching cycle. Compared with case II and case III, the power unit operating cost, CHP unit operating cost and wind curtailment cost have all decreased in case I. In the scheduling cycle, the total operating cost of case $\mathrm{I}$ is reduced by $0.7 \%$ compared with case II and $3.6 \%$ compared with case III. Case I has $65 \mathrm{MW}$ less wind curtailment than case II, and 339MW less wind curtailment than case III. The dispatching scheme under case 1 can reduce wind curtailment, and the total operation cost is reduced.

Table 3. operational cost under 3 cases

\begin{tabular}{cccc}
\hline $\begin{array}{c}\text { Cost/thousand } \\
\text { yuan }\end{array}$ & $\begin{array}{c}\text { Power } \\
\text { unit }\end{array}$ & $\begin{array}{c}\text { CHP } \\
\text { unit }\end{array}$ & $\begin{array}{c}\text { wind } \\
\text { curtailment }\end{array}$ \\
\hline caseI & 2364.5 & 2159.1 & 22.6 \\
caseII & 2377.6 & 2166.4 & 35.6 \\
caseIII & 2377.6 & 2229.7 & 103.4 \\
\hline
\end{tabular}

\subsection{Wind power consumption analysis}

The optimization results of the electrical power in the three cases are shown in Fig. 5-7. Comparing Fig. 5-7 and Fig. 4, it can be seen that during the period of 1:008:00 when the wind power is relatively high, the heat load is relatively high, which leads to a relatively highpower output generated by the CHP unit. Power units have minimum power generation that cannot be further peaked, resulting in insufficient space for the system to absorb wind power.

In case II, equipped with electric boilers, the excess wind power can be used for heating, which increases the wind power consumption, reduces the necessary power generated by the CHP unit. Considering the thermal flexibility of the heating network, the CHP can adjust its power output according to the variations of wind power. For example, during the periods of high wind power and low electrical load, CHP appropriately reduce their own power and heat output to increase wind power consumption, and at the same time, the insufficient heat output is suppressed by the heat network. Case I has been coordinated by the source and network of the electricity-heat integrated energy system, and the electricity load is more provided by wind power, achieving the wind power consumption. 


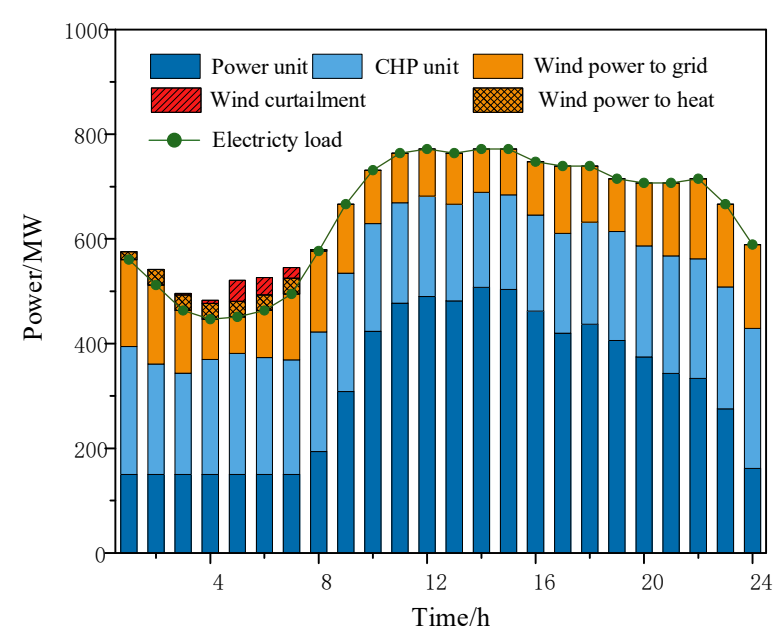

Fig. 5. Electric power optimization result in case I

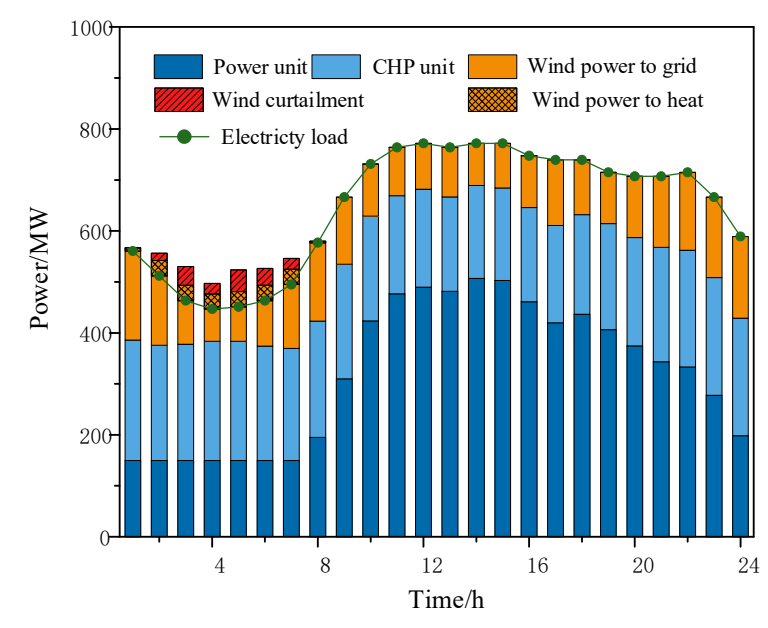

Fig. 6. Electric power optimization result in case II

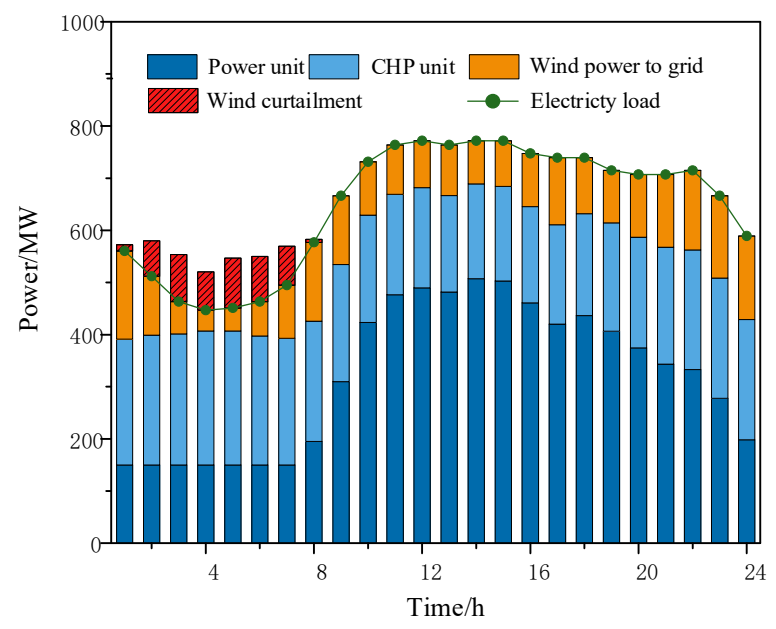

Fig. 7. Electric power optimization result in case III

\section{Conclusion}

This paper proposed an optimal scheduling method for IPHS with multiple thermal flexibilities. A detailed formulation of the DHN model is proposed as a quasidynamic model. The results of case study show that our scheduling method can reduce the total cost and improve wind accommodation for IPHS. And both the flexibility of electric boiler and DHN can enhance IPHS operational flexibility.

\section{Acknowledgements}

This work was financially funded by the Science and Technology Project of Hangzhou Yineng Electric Power Technology Co., Ltd (EPRD2019-11).

\section{References}

1. H. Jia, Y. Mu, X. Yu. Thought about the integrated energy system in China. Electric Power Construction 36(01), 16-25 (2015)

2. K. Peng, C. Zhang, B. Xu, et al. Status and prospect of demonstration project of multi-energy synergy integrated energy system. Electric Power Automation Equipment 37(06), 3-10 (2017)

3. Q. Lyu, H. Jiang, T. Chen, et al. Wind power accommodation by combined heat and power plant with electric boiler and its national economic evaluation. Automation of Electric Power Systems 38(01), 6-12 (2014)

4. F. Xun, Y. Min, L. Chen. Combined electricity-heat operation system containing large capacity thermal energy storage. Proceedings of the CSEE 34(29), 5063-5072 (2014)

5. W. Gu, J. Wang, S. Lu, et al. Optimal operation for integrated energy system considering thermal inertia of district heating network and buildings. Applied Energy 199, 234-246 (2017)

6. M. Kouhia, T. Laukkanen, H. Holmberg, et al. District heat network as a short-term energy storage. Energy 177, 293-303 (2019)

7. M. Wang, Y. Mu, X. Meng, et al. Optimal Scheduling Method for Integrated Electro-thermal Energy System Considering Heat. Power System Technology 44, 132-140 (2020)

8. Y. Zhou, W. Hu, Y. Min, et al. Integrated Power and Heat Dispatch Considering Available Reserve of Combined Heat and Power Units. IEEE Transactions on Sustainable Energy 10(3), 13001310 (2019)

9. W. Wang, L. Yang, L. Wang, et al. Optimal Dispatch of Integrated Electricity-Heat Energy System Considering Heat Storage Characteristics of Heating Network. Automation of Electric Power Systems 42(21), 45-52 (2018)

10. Y. Zhang, Q. Lyu, Y. Li, et al. Analysis on Operation Flexibility of Combined Heat and Power Plant with Four Improved Power-Heat Decoupling Schemes. Automation of Electric Power Systems 44(02), 164-172 (2020) 